\title{
TÓPICOS DE DIREITO PROCESSUAL LITISPENDÊNCIA POR IDENTIDADE DE CAUSA DE PEDIR
}

\author{
LEONARDO GRECO \\ THEOPHILO ANTONIO MiguEL FILHO
}

I - Problemática. II - Objetivos. III - Justificativa. IV - Metodologia e técnicas utilizadas. V - Desenvolvimento. VI - Conclusão. VII Bibliografia.

\section{I- Problemática}

Em virtude da pesada carga tributária imposta pelo Governo, vem se tornando freqüente a utilização, por parte dos contribuintes, das vias judiciais em busca de um provimento jurisdicional que os desonere do recolhimento de determinado tributo.

O problema surge quando o Poder Judiciário não lhes dá guarida, mas, mesmo assim, os contribuintes, mormente as pessoas jurídicas, insistem em fazer prevalecer, a todo custo, os argumentos que dão supedâneo à pretensão esposada em juízo, por intermédio de brechas existentes na interpretação da legislação processual.

Uma das vias mais largamente utilizadas é o mandado de segurança, em virtude de seu rito sumaríssimo, que comporta provimento judicial initio litis, bem como da benesse legal da prioridade para julgamento. ${ }^{1}$

Uma das técnicas utilizadas consiste em decompor a tese autoral em tantos argumentos quantos bastem para fazê-la bem sucedida, ainda que, para tanto, mais de uma ação mandamental tenha que ser ajuizada com o intuito de se alcançar o mesmo resultado prático.

Ocorre que, em regra, a autoridade impetrada é a mesma, deparando-se esta com dois mandados de segurança versando sobre o mesmo assunto, verbi gratia, pretensão desconstitutiva de notificação fiscal de lançamento de débito. $O$ caso é

1 Artigo 17, caput, da Lei 1.533, de 31 de dezembro de 1951.

R. Dir. Adm., Rio de Janeiro, 228: 183-193, Abr./Jun. 2002 
levado ao Poder Judiciário, em sede de preliminar de mérito nas informações prestadas. para pronunciamento acerca da existência de possível litispendência. Indigitado óbice é refutado pelo impetrante, ao argumento de se tratar de ações distintas, por diversidade da causa petendi.

\section{II- Objetivos}

Ao final do presente trabalho, restará demonstrado que a causa de pedir não pode ser desdobrada em diversos argumentos, gerando diversas ações e oportunidades para obtenção do sucesso de uma tese autoral, eis que com eles não se confunde.

\section{III - Justificativa}

A importância deste estudo se justifica para preservar a integridade de diversos princípios processuais. como o do juiz natural, o da livre distribuição, o da lealdade processual, bem como a coisa julgada, coibindo a proliferação de práticas processuais que enfraqueçam a segurança jurídica e a credibilidade dos pronunciamentos judiciais.

\section{IV - Metodologia e técnicas utilizadas}

A pesquisa jurisprudencial e doutrinária, inclusive com abordagens relativas ao Direito Comparado, será o método utilizado para se alcançar a conclusão.

\section{$V-$ Desenvolvimento}

Objetivando atingir a melhor compreensão acerca da matéria, admitamos que uma pessoa jurídica impetre ação mandamental contra ato do Chefe da Divisão de Arrecadação do Instituto Nacional de Seguridade Social - INSS, objetivando ser desobrigada do recolhimento do adicional de $2,5 \%$, incidente sobre a contribuição previdenciária devida, instituído pelo art. $22, \S 1^{\circ}$, da Lei $n^{\circ} 8.212 / 91$, em relação às parcelas vencidas ou vincendas, pelo fato da cobrança do indigitado acréscimo violar o princípio da isonomia, uma vez que confere tratamento tributário desigual a contribuintes que têm a mesma capacidade contributiva.

Uma vez proferida sentença de mérito denegando a segurança, retorna ao Poder Judiciário mediante novo ajuizamento, sustentando, dessa vez, não ser sociedade seguradora e, consequientemente, sujeito passivo da relação jurídica de natureza tributária.

Aduz a Impetrante, como causa petendi, que a pretensão ora deduzida baseia-se na premissa de não ser sociedade seguradora, portanto, contribuinte do tributo em questão. 
Assim, afirma que se tem como arbitrária e ilegal a iminente cobrança que está para ser ajuizada, tendo a Impetrante sofrido sérios danos em razão da inscrição de tal débito em dívida ativa, com o consequiente indeferimento de expedição de certidão negativa de débitos fiscais.

Daí se serve de outro writ of mandamus, objetivando a concessão de ordem judicial para afastar a cobrança do adicional de $2,5 \%$, regulado pelo art. $22, \S 1^{\circ}$, da Lei $n^{\circ} 8.212 / 91$, haja vista não se enquadrar nas hipóteses previstas em lei para tal cobrança, por não ser sociedade seguradora.

"La litispendencia es uno de esos temas clásicos que siempre ha estado ahí Fácil de identificar, de uso cotidinao en el foro, polémico en muchos aspectos concretos, condicionante de otras intituciones."

(Francisco Ramos Méndez)

A litispendência e a coisa julgada são dois institutos processuais afins cujo objetivo é obter segurança jurídica e estabilidade nas relações sociais, evitando a perpetuação dos conflitos de interesse.

Encontram-se definidos pela lei processual civil nos três primeiros parágrafos do artigo 301. Com efeito, "verifica-se a litispendência ou a coisa julgada, quando se reproduz ação anteriormente ajuizada", sendo que "uma ação é idêntica à outra quando tem as mesmas partes, a mesma causa de pedir e o mesmo pedido. Há litispendência, quando se repete ação que está em curso; há coisa julgada quando se repete ação que já foi decidida, de que não caiba recurso."

Destarte, competindo ao réu, antes de discutir o mérito, alegá-las (artigo 301, incisos V e VI), incumbe ao juiz extinguir o processo, independentemente de apreciação meritória, quando acolher a alegação, a teor da norma autorizadora insculpida no inciso $\mathrm{V}$ do artigo 267 da Lei Adjetiva.

Daí exsurge a importância da precisa identificação dos elementos subjetivo, objetivo e causal da ação, vale dizer, por intermédio da perfeita identidade das partes, pedido e causa de pedir, poder-se-á identificar quando uma ação é idêntica a outra.

A causa de pedir consubstancia-se nos fatos e fundamentos jurídicos do pedido, assim conforme definido pelo inciso III do artigo 282 do Código de Processo Civil

Segundo Eduardo Arruda Alvim, "responde à tradição do direito brasileiro, e, em realidade, representa posição universal, a de que, para se identificar uma ação, é absolutamente imprescindível examinarem-se os fatos e os fundamentos jurídicos em que se baseia esta ação (causa de pedir), os quais, são, a seu turno, os fatos e os fundamentos jurídicos do pedido, nos quais se deve assentar a sentença que haja julgado essa ação, agora em forma de sua fundamentação. Uma ação deve ser identificada à luz de sua substância, que são os atos jurídicos ocorridos (teoria da substanciação)." 2

2 Curso de Direito Processual Civil, volume 1, Editora Revista dos Tribunais, 1999. 
José Carlos Barbosa Moreira ${ }^{3}$ afirma que a identificação da causa petendi coincide com a resposta às perguntas: por que o autor pede tal previdência? Qual o fundamento de sua pretensão? Prossegue a definindo como o fato ou conjunto de fatos a que o autor atribui a produção do efeito jurídico por ele afirmado, sendo que não integram a causa de pedir a qualificação jurídica dada pelo autor ao fato em que apoia sua pretensão e a norma jurídica aplicável à espécie.

Destarte, segundo Luiz Fux, "se o autor promove uma ação visando à anulação de uma escritura, alegando erro e não obtém êxito, não pode, posteriormente, propor a mesma ação com base nos mesmos fatos, sob a invocação de que o que houve foi dolo. Nesta hipótese, o autor estaria apenas alterando a qualificação jurídica do fato e não a sua consequiência jurídica que é o desfazimento do vínculo, mercê de repetir a mesma base fática, incidindo na vedação das ações à luz da teoria da substanciação." 4

Para Araken de Assis 5 "é rigorosamente neutro o fundamento legal, ou nomen iuris, na expressão de certa doutrina, na caracterização da causa petendi. Deriva tal certeza de antigo e obscuro brocardo - iura novit curia - que atribui exclusivamente ao órgão jurisdicional o dever de joeirar os fatos e encontrar a regra jurídica na qual, supostamente, incidiram."

Prossegue afirmando que "no que tange à cumulação de ações, admitir a indiferença do fundamento legal implica identificar uma única ação, se o autor, após expor o complexo de fatos, invoca duas ou mais regras jurídicas para designar a conseqüência reconhecida neste material. Daí, se alguém se vitimou em acidente de trânsito quando era passageiro de um ônibus e, na ação de reparação de seus prejuízos, aponta tanto o artigo 159 quanto artigo 1.056 do $\mathrm{CCB}$ como regras que autorizam o pedido, trata-se de uma única ação."

Segundo Antônio Carlos De Araújo Cintra, Ada Pellegrini Grinover, Cândido Rangel Dinamarco", "vindo o juízo, o autor narra os fatos dos quais deduz. Ter o direito que alega. Esses fatos constitutivos, a que se refere o artigo 282, inciso III, do Código de Processo Civil (...) também concorrem para a identificação da ação proposta (...).

O fato que o autor alega (...) recebe da lei determinada qualificação jurídica (...). Mas o que constitui a causa petendi é apenas a exposição dos fatos, não sua qualificação jurídica. Por isso é que, se a qualificação jurídica estiver errada, mas mesmo assim o pedido formulado tiver relação com os fatos narrados, o juiz não negará o provimento jurisdicional. (...). O direito brasileiro adota, quando à causa de pedir, a chamada doutrina da substanciação, que difere da individuação, para a qual o que conta para identificar a ação proposta é a espécie jurídica invocada (...), não as meras "circunstâncais de fato' que o autor alega."

3 O Novo Processo Civil Brasileiro, 15 edição, Editora Forense, 1993.

4 Curso de Direito Processual Civil, Editora Forense, 2001.

5 Cumulação de Ações, $1^{2}$ edição - $2^{a}$ tiragem, Editora Revista dos Tribunais, 1991.

6 "Teoria Geral do Processo", 9" edição, 2 tiragem, Malheiros Editores, 1993. 
Para Humberto Theodoro Junior ${ }^{7}$ "a causa petendi, por sua vez não é a norma legal invocada pela parte, mas o ato jurídico que ampara a pretensão deduzida em juizo.

Todo direito nasce do fato, ou seja, do fato a que a ordem jurídica atribui um determinado efeito. A causa de pedir, que identifica uma causa, situa-se no elemento fático e em sua qualificação jurídica. Ao fato em si dá-se a denominação de 'causa remota' do pedido; e à sua repercussão jurídica, a de 'causa próxima' do pedido.

Para que sejam duas causas tratadas como idênticas é preciso que sejam iguais tanto a causa próxima como a remota."

Na hipótese vertente, insurge-se a impetrante contra ato administrativo que a autuou pelo não recolhimento do adicional incidente sobre a contribuição previdenciária prevista na Lei ${ }^{\circ} 8.212 / 91$. Dessa autuação exsurgiram alguns efeitos, dentre eles, a constituição do crédito tributário e o conseqüente indeferimento do pedido de expedição de certidão negativa de débito. Este decorreu daquele. Em verdade, o fato é único, mas com desdobramento lógicos.

Para impugná-lo, a demandante valeu-se da ação mandamental, obtendo pronunciamento jurisdicional desfavorável. Sua primeira tese autoral repousou em suposta violação ao princípio da isonomia.

Após a prolação da sentença, comparece a outro Juízo, atacando o mesmo ato administrativo, todavia, como novos argumentos jurídicos.

Nessa nova oportunidade, alega não ser contribuinte do adicional de $2.5 \%$, incidente sobre a contribuição social, instituído pelo art. $22, \S 1^{\circ}$, da Lei $n^{\circ} 8.212 / 91$, por não ser sociedade seguradora.

Data venia, tal expediente é inviável tecnicamente, além de atender contra os princípios processuais do juiz natural, da lealdade e da boa fé. Ao demandante não é dado deduzir sua pretensão parceladamente, revelando paulatinamente argumentos para dar supedâneo à sua demanda, à medida em que os anteriores são rechaçados.

Em elucidativa hipótese, "se alguém propõe ação declaratória de investigação de paternidade alegando concubinato (art. 363 , I, do CCB) entre a mãe do investigante e o investigado, poderia o juiz, não obstante a falta de prova do concubinato, julgar procedente a ação porquanto, na instrução, se provou a existência de relações entre aquelas pessoas na época própria da concepção? $\mathrm{E}$ indicando o autor, desde logo, na inicial, o concubinato e as relações sexuais (art. 363, II, CCB), ter-se-ia cumulação de ações ou uma ação com dois fundamentos? Inclina-se Ovídio A. Baptista da Silva pela última solução e aduz: " a circunstância de estarem os fundamentos de uma mesma demanda distribuidos por dois ou mais dispositivos legais, não implicará que existam necessariamente tantas ações quantos sejam os preceitos legais em causa," (grifo nosso).

Conforme José Rogério Cruz e Tucci ${ }^{8}$, “diferentemente de outras legislações, em especial a alemã e a italiana, nas quais sempre predominou a liberdade das partes na apresentação de suas respectivas alegações, é da tradição do processo

7 "Curso de Direito Processual Civil", Vol. I, $19^{2}$ edição, Editora Forense.

8 A causa petendi no Processo Civil, Editora Revista dos Tribunais, 1993. 
brasileiro a adoção da regra da eventualidade, impondo aos desmandantes o dever de propor, num mesmo momento, todos os meios de ataque e defesa. Como anota Liebman, o nosso processo civil, fiel às suas origens, manteve dois postulados herdados do processo comum medieval: o de uma ordem legal necessária das atividades processuais, como uma sucessão de estádios ou fases diversas, nitidamente separadas entre si; e o princípio da eventualidade, que obriga as partes a propor ao mesmo tempo todos os meios de ataque ou de defesa, ainda que contraditórios entre si". (grifo nosso)

Ensina Ernane Fidélis dos $\operatorname{Santos}^{9}$ que "o processo não é apenas instrumento de solução de litígios, no interesse das partes. É também meio de que o Estado se utiliza para impor a paz social. Dai não fiar o processo a critério das partes, a ponto de lhes permitir o uso desregrado de expedientes fraudulentos, procrastinatórios e imorais, para conseguir seus objetivos (...)."

Com efeito, na exata dicção do mandamento insculpido no artigo 14 , inciso II, da lei Adjetiva, compete às partes e a seus procuradores proceder com lealdade e boa fé.

Ademais, há evidente litispendência, conforme anteriormente definido.

Comparando as duas ações mandamentais, as partes, o fato e o objeto são os mesmos. O que varia são os argumentos dos quais se vale o autor para obter o provimento judicial pretendido.

Em voto da lavra do Eminente Relator Francisco de Assis Vasconcellos Pereira da Silva, na Apelação número 492.544-0, 2 de julho de1992, decidiu a $7^{\text {a }}$ Câmara do $1^{\circ}$ Tribunal de Alçada Cível do Estado de São Paulo que "o fato e o fundamento jurídico do pedido (direito afirmado pela autora) integram a causa de pedir, que por força da adotada teoria da substanciação haverá de se conservar inalterada durante todo o processo. Entretanto, não integram a causa de pedir os argumentos em que a autora se baseia para sustentar os fundamentos do pedido. A propósito, calha precisamente a explicação do ilustre Professor José Ignacio Botelho de Mesquita, constante de parecer veiculado Revista dos Tribunais 564/41: 'Do mesmo modo, não se confunde o fato constitutivo do direito, que é a hipótese de fato previsto na lei como necessária e suficiente para gerá-lo, com os argumentos de fato com que o autor procura demonstrar a ocorrência daquela hipótese, o que os italianos denominam fattispecie di legge. Daí a afirmação de Pontes de Miranda, transcrita na sentença: simples mudança de fato na sustentação dos fundamentos da ação não constitui alteração do pedido." 10 (grifo nosso)

$\mathrm{Na}$ Apelação 146.089-1/4, $2^{\mathrm{a}}$ Câmara Cível do Tribunal de Justiça do Estado de São Paulo, em 20 de agosto de 1991, afirmou o Eminente Relator Silveira Paolo: “... Não se pode olvidar que, 'Passada em julgado a sentença de mérito, reputar-se-ão deduzidas e repelidas todas as alegações e defesas, que a parte poderia opor assim ao acolhimento como à rejeição do pedido'. É o que diz o artigo 474 do CPC... Enfática, ainda, nesse

9 Manual de Direito Processual Civil, Vol. I, $4^{\text {a }}$ edição, Editora Saraiva.

10 No mesmo sentido, vide acórdão do $2^{\circ}$ Tribunal de Alçada Cível na Apelação 211.720-8, $5^{a}$. Câmara, 22.12.87, Relator, Alves Bevilacqua: JTACSP: JTACSP, Leix, 110/286. 
sentido, a lição da Egrégia Quarta Câmara Civil deste Tribunal: 'Quando examina se ocorre ou não nulidade de arrematação, o juiz não fica adstrito aos fundamentos invocados pela parte. Esta apenas aponta o fato. O juiz lhe dá o Direito: Da mihi factum, dabo tibi ius. Se foi decidido que a praça não é nula porque não houve irregularidade da arrematação, não pode a parte volver a juízo esposando a mesmas pretensão e variando apenas ofundamento' (cf. RT 605/46)". (grifo nosso)

Em ambas o fato jurídico é único: autuação do impetrado pela entidade autárquica previdenciária, sendo que por intermédio do Poder Judiciário quer ver desconstituída. A obtenção de certidão negativa de débito não consubstancia pretensão autônoma, mas mera consequiência do acolhimento da primeira.

Para tanto, se vale de diversos argumentos desdobrados para fundamentar sua pretensão desconstitutiva, enquanto deveria utilizá-los de uma só vez, sob pena de estar maculando a salutar disciplina do artigo 474 do Código de Processo Civil, dispositivo este que alberga os princípios da igualdade processual (artigo 125, inciso I, do Código de Processo Civil) e da paridade de armas, que informam o direito processual como um todo.

O supra indigitado artigo 474, ao estabelecer que "passada em julgado sentença de mérito, reputar-se-ão deduzidas e repelidas todas as alegações e defesas que a parte poderia opor assim ao acolhimento como à rejeição do pedido", está a, verdadeiramente, consagrar o princípio da eventualidade, inserido no artigo $300 \mathrm{da}$ Lei Adjetiva, às avessas. Resta, assim, assegurado o tratamento isonômico preconizado pelo artigo $5^{\circ}$, caput, da Constituição da República.

Nesse diapasão, pode-se categoricamente afirmar, em síntese, a fim de definir o preciso conceito de litispendência, que a causa de pedir não se confunde com os argumentos dos quais se vale o demandante para embasar a pretensão deduzida. Afigura-se inconcebível admitir que a tese autoral seja desmembrada em diverso argumentos e pulverizada ao longo de tantos processos quantos sejam necessários até ulterior sucesso, pois tal expediente acarreta prejuízo para a defesa de réu e colide frontalmente com o princípio do juiz natural.

Insatisfeito com a improcedência da pretensão deduzida, ao demandante não é permitido alterar seus argumentos e ajuizar nova (rectius: a mesma, em verdade) ação perante outro Juízo, a fim de, em uma Segunda tentativa, obter outra chance de sucesso.

Com efeito, os argumentos técnico - jurídicos dos quais se utiliza o demandante para dar supedâneo à tese esposada não se prestam à individualização da causa de pedir, sob pena de se admitir o desmembramento em tantos ações quantas forem os diversos argumentos, em evidente afronta aos ditames do artigo $474 \mathrm{e}$, por conseguinte, aos princípios processuais da lealdade, boa fé e igualdade das partes.

A argumentação jurídica não integra a individualização da causa petendi. A qualificação jurídica se inclui na motivação ou fundamentação jurídica da pretensão, mas não na individualização da causa de pedir nem, por fim, no objeto do processo.

há que se observar que o efeito prático a ser alcançado com a tutela estatal é rigorosamente o mesmo nas duas ações entre as quais sustenta-se a ocorrência de litispendência. 
Impende trazer à colação a elucidativa lição de Francisco Málaga Diéguez ${ }^{11}$, in verbis:

Por último, es preciso subrayar que la causa petendi compreende únicamente hechos: la calificación y argumentación jurídicas no íntegran el objeto del juicio, sino más bien la fundamentación o motivación de la demanda, ya que los elementos jurídicos alegados en la misma no vinculan al Juez por obra de los aforismos iura novit curia y da milhi factum et dabo tibi ius. No pretende negarse aquí el importante papel que la norma jurídica juega en la configuración de la causa de pedir, pues es evidente que ésta sólo compreende aquellos hechos que, al originar e individualizar la acción que se ejercita, han sido previstos por dicha norma como imprescindibles para la concesión de la tutela judicial que e pretende. Sin embrgo, esta exigencia de relevancia normativa no impide distinguir los hechos de su fundamentación jurídica, de suerte que, si los primeros coinciden en sendos juicios, la divergencia en uno de los elementos de la Segunda (denominación de la acción, calificación jurídica) no obsta en modo alguno a la existencia de identidad causal. En este punto, debe suscribirse por tanto la teoría de la sustanciación, en demérito de la teoría de la individualización, según la cual sólo integram la causa petendi 'el derecho o razones jurídicas determinantes de lo que se pide', asi como de la denominada teoría sincrética, según cuyos postulados la causa de pedir ha de estar 'fácticamente sustanciada y juridicamente individualizada'.

En la dirección que aquí se propone apunta como uno parte de la jurisprudencia más reciente de la Sala $1^{a}$ del Tribunal Supremo, que conceptúa la 'causa petendi' como 'el relato fáctico que fundamenta la acción y desemboca unas concretas peticiones.' No obstante, también existen numerosas sentencias en las que parece suscribirse la mencionada teoría sincrétia, al afirmarse que integran dicha causa los hechos y su calificación jurídica. A pesar de estos últimos pronunciamientos, debe concluirse que, si en dos juícios se formula la misma pretensión entre las mismas partes, basada en los mismos hechos individualizadores, el mero cambio de calificación jurídica no altera ni transforma la causa de pedir, y por tanto el segundo Juez deberá admitir lo eficacia excluyente de la litispendencia."

Conforme recente pesquisa na jurisprudência italiana (Rivista di Diritto Processuale, ano LXIII, número 2, abril a junho de 1998, página 545/577),

Em caso de ação declatória tendo por objeto a validade de um negócio, a sentença de procedência preclui ao réu rediscutir tal relação, exercitando em separado juízo que pretenda anulá-la que podia e sabia poder exercitar já no curso do primeiro processo.

11 La Litispendencia, José Maria Bosch Editor, Barcelona, 1999. 
Segundo Ernesto Fabiani ${ }^{12}$, tal solução parece impor-se por força.

- do princípio pelo qual o julgado cobre (não só o deduzido mas também) o deduzível, a menos que se queira anular este princípio;

- do princípio - prevalente seja em doutrina seja em jurisprudência - pelo qual o julgado preclui mesmo as ações relativas a direitos diversos daquele declarado, mas com ele incompatíveis - quer tenham eficácia impeditiva, modificativa ou extintiva a respeito da situação subjetiva deduzida - e deduzíveis em via de exceção ou de demanda reconvencional no primeiro processo (na espécie, direitos do réu de impugnativa do negócio declarado existente);

— da própria essência do julgado, que se veria de outro modo tornada vã se se considerasse possível que o "bem da vida" por ele atribuído possa sucessivamente ser reposto em discussão através da instauração de um novo juízo.

Vejamos, agora, elucidativos posicionamentos jurisprudenciais, que denotam a distinção que ora se pretende demonstrar.

"Filiação. Segunda ação de investigação da paternidade. Causa de pedir da primeira distinta da 'causa pretendi' da segunda. Inexistência de ofensa à coisa julgada. CCB, art. 363.

Pelo disposto nos incisos do artigo 363 do CCB, o filho dispõe de três fundamentos distintos e autônomos para propor a ação de investigação da paternidade. O fato de ter sido julgada improcedente a primeira ação que teve como causa de pedir a afirmação de que ao tempo da sua concepção a sua mãe estava concubinada com seu pretendido pai, não lhe impede de ajuizar uma segunda demanda, com outra 'causa petendi', assim entendida que a sua concepção coincidiu com as relações sexuais mantidas por sua mãe com seu pretendido pai.

São dois fundamentos diferentes, duas causas de pedir distintas, e a admissibilidade do processamento da segunda ação não importa em ofensa ao princípio da autoridade da coisa julgada." 13

"Processual Civil. Administrativo. Mandado de Segurança. Servidora Pública Estadual. Remoção. Litispendência. Ocorrência.

- O mandado de segurança, embora seja uma ação de natureza constitucional destinado a proteção de direito líquido e certo contra ilegal ou abusivo de poder emanado de autoridade pública, é regulado subsidiariamente pelo Código de Processo Civil e, portanto, deve submeter-se ao comando do artigo $267, V$, que prevê a extinção do processo sem julgamento de mérito quando verificado o instituto da litispendência.

12 Interesse ad agire, mero accertamento e limiti oggettivi del giucato, Rivista di Diritto Processuale, ano LXIII, número 2, abril a junho de 1998, página 546/577.

13 Superior Tribunal de Justiça, Recursos Especial 112.101-RS, Rel. Min. Cesar Asfor Rocha, j. 29/6/00, DJ 18/9/00. 
- Nos termos da nossa lei instrumental civil, reputam-se idênticas duas ações quando houver identidade entre as partes, a causa de pedir e o pedido (art. $301, \S 2^{\circ}$, do CPC).

- Em consonância com tais conceitos, ocorre a litispendência na hipótese em que servidora pública estadual postula o reconhecimento do direito à remoção para acompanhar marido, funcionário público estadual lotado na Secretaria de Fazenda, reproduzindo pleito formulado em ação mandamental anteriormente ajuizada, em curso, sendo irrelevante, 'in casu', os novos documentos anexados quanto a situação funcional e residencial de seu cônjuge.

- Recurso ordinário desprovido." 14

\section{$V I-$ Conclusão}

O mesmo fato jurídico pode render ensejo a diversas consequiências. A fim de impugná-las, o jurisdicionado não pode desmembrar sua pretensão ao longo de diversos argumentos para engendrar, supostamente, distintas ações, sob pena de investir contra o mandamento processual insculpido no artigo 474 da Lei Adjetiva.

Com efeito, o princípio da eventualidade existe para ambos os litigantes, com vistas a preservar a igualdade dos mesmos, segurança jurídica e consecução da estabilidade nas relações sociais.

Logo, conforme o caso, existirá coisa julgada ou litispendência quando o demandante retornar o Juízo, com novos argumentos, mas atacando o mesmo fato jurídico gerador de sua irresignação e suas diversas consequiências. Nesse diapasão, é de se acolher preliminar de litispendência ou coisa julgada para extinguir o segundo processo, sem julgamento do mérito, na forma autorizadora do artigo 267, inciso VI, do Código de Processo Civil.

\section{VII - Bibliografia}

ALVIM, Eduardo Arruda. Curso de Direito Processual Civil. Volume I. São Paulo, Editora Revista dos Tribunais, 1999.

ASSIS, Araken de. Cumulação de ações. $1^{\mathrm{a}}$ edição - $2^{\mathrm{a}}$ tiragem. São Paulo, Editora Revista dos Tribunais, 1991.

BOTELHO DE MESQUITA, José Ignácio. Conteúdo da causa de pedir. in" Consultas e Pareceres. São Paulo, Revista dos Tribunais, 564:41-51, outubro de 1982. CINTRA, Antonio Carlos de Araújo; GRINOVER, Ada Pellegrini \& DINAMARCO, Cândido Rangel. Teoria Geral do Processo, $9^{\mathrm{a}}$ edição $-2^{\mathrm{a}}$ tiragem. São Paulo, Malheiros Editores, 1993.

14 Superior Tribunal de Justiça, Recurso Ordinário em Mandado de Segurança $n^{\circ} 8.240$ - MG, Relator Ministro Vicente Leal, Sexta Turma, data da decisão 24 de junho de 1999. 
DIÉGUEZ, Francisco Málaga. La Litispendencia. Barcelona, José Maria Bosch Editor, 1999.

FABIANI, Ernesto. Interesse ad agire, mero accertamento e limiti oggettivi del giudicato. Rivista di Diritto Processuale, ano LXIII, número 2, abril a junho de 1998, páginas 545-577.

FUX, Luiz. Curso de Direito Processual Civil. Rio de Janeiro, Editora Forense, 2001.

GIDI, Antonio, Coisa julgada e litispendência em ações coletivas, São Paulo, Editora Saraiva, 1995.

MOREIRA, José Carlos Barbosa. O Novo Processo Civil Brasileiro. $15^{\mathrm{a}}$ edição. Rio de Janeiro, Editora Forense, 1993.

SANTOS, Ernane Fidélis dos. Manual de Direito Processual Civil. Volume 1. $4^{\mathrm{a}}$ edição. São Paulo, Editora Saraiva, 1996.

THEODORO JÚNIOR, Humberto. Curso de Direito Processual Civil. Volume I. $19^{\mathrm{a}}$ edição. Rio de Janeiro, Editora Forense, 1997.

TUCCI, José Rogério Cruz e. A causa petendi no Processo Civil. São Paulo, Editora Revista dos Tribunais, 1993. 


\section{Família e Igualdade}

Carlos David S. Aarão Reis

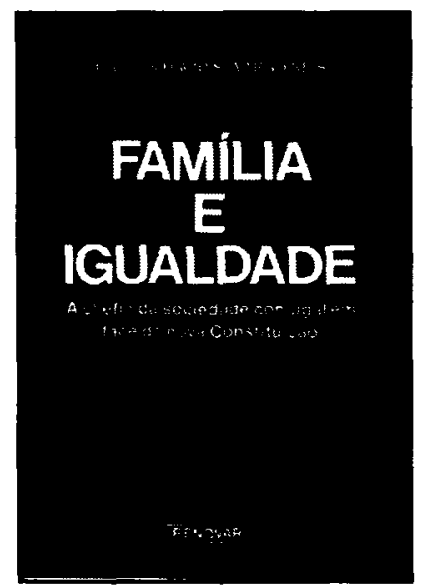

A leitura deste livro fixa, com muita propriedade, a noção de um tema em que muitos falam e poucos assimilam: a igualdade. Enfrentando a questão proposta de forma definitiva, com rigorosa competência e absoluto domínio da doutrina e valendo-se, ainda, de impecável metodologia. Esta obra representa admirável contribuição às letras jurídicas nacionais.

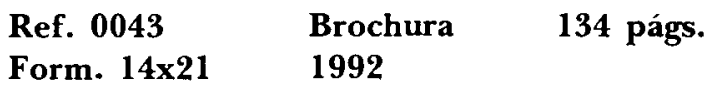

\section{Filosofia do Direito}

Nelson Saldanha

Este livro apresenta, dentro de uma linha temática bastante ampla e abrangente, os temas fundamentais da filosofia do direito. Sem recorrer a uma exposição puramente histórica das matérias, que em tantos casos substitui a reflexāo sistemática, a obra se baseia contudo sobre um tratamento substancialmente histórico dos problemas, vistos sob angulação didática e ao mesmo tempo pessoal. Incluindo as questões epistemológicas, as ontológicas e as axiológicas, o livro conduz a uma série de itens sobre hermenêutica jurídica, envolvendo o hoje tão discutido tema das normas e dos princípios.

Ref. 0159

Form. 14x21

Brochura 1998
236 págs.

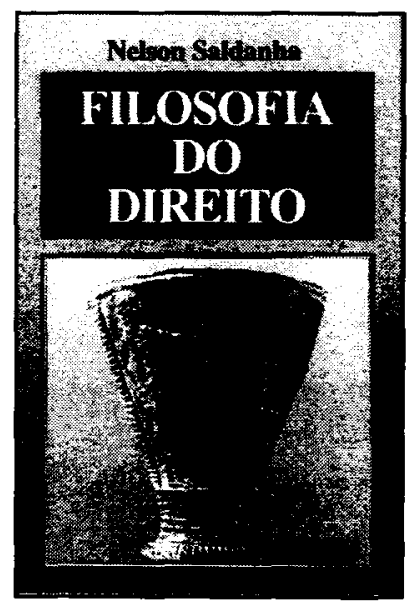

